\title{
The relationship between biological function and teleology: Implications for biology education
}

\author{
Friederike Trommler ${ }^{*}$ (i) and Marcus Hammann (i)
}

\begin{abstract}
This paper explicates the relationship between biological function and teleology by focusing not only on difference but also on conceptual overlap. By doing so, this paper is meant to increase awareness of the misleading potential of biological function and the educational necessity to explicate the meaning of biological function to biology students to prevent them from drawing inadequate teleological conclusions about biological phenomena. The conceptual overlap between teleology and biological function lies in the notion of telos (end, goal). Biologically inadequate teleology assumes that teloi (ends, goals) exist in nature and that natural mechanisms are directed towards teloi. Such inadequate teleological assumptions have been documented in students' reasoning about biological phenomena. Biological function, however, does not involve the assumption that teloi exist in nature. Rather, biologists use the notion of telos as an epistemological too/ whenever they consider a structure or mechanism functional because they view this structure or mechanism as a means to an end (telos). Whereas for biologists such means-ends conceptualizations represent a productive tool for identifying biological phenomena functionally, for students, such means-ends considerations can be misleading. Therefore, this paper explicates how far the concept of biological function involves reference to ends (teloi) and how it relates to biological mechanisms. The paper draws implications on how to prevent students from slipping from functional reasoning into inadequate teleological reasoning.
\end{abstract}

Keywords: Function, Teleology, Causality, Mechanism

\section{Background}

Teleological reasoning, i.e., reasoning based on the assumption that structures and mechanisms exist for a specific purpose, function, end, or goal is considered a major learning obstacle in biology education (Evans et al. 2012; Kampourakis and Zogza 2008; Kelemen 2012; Sinatra et al. 2008). While teleological reasoning about human-made artifacts is adequate because artifacts are made for specific purposes, biological phenomena (biological structures as well as mechanisms) have not been designed for specific purposes. However, biology students easily rely on purpose and design when they

*Correspondence: trommler@uni-muenster.de

Centre for Biology Education, University of Münster, Schlossplatz 34,

48143 Münster, Germany reason about biological phenomena (Kampourakis et al. 2012b; Mead and Scott 2010). For example, when reasoning about evolutionary change, students tend to consider the function of a particular trait and the organism's need for that function the only cause for evolutionary change rather than that the students refer to the evolutionary selection mechanism (Kampourakis and Zogza 2008, 2009; Jensen and Finley 1996; Pedersen and Halldén 1994; Gresch and Martens 2019; Tamir and Zohar 1991; Bishop and Anderson 1990; Nehm and Ridgway 2011). Of course, one might argue that the functionality of an ancestors' trait did indeed play a causal role in the evolutionary process. Problematic about the students' teleological reasoning, however, is the fact that they provide the function of a trait as the one and only causal factor for how the trait came into existence without linking 
the function to the evolutionary selection mechanism. The problem of teleological reasoning is not restricted to evolution, it has also been documented in connection with plant physiology (Abrams and Southerland 2001; Tamir and Zohar 1991), human physiology (Michael 1998; Trommler et al. 2018), and ethology (Abrams and Southerland 2001; Tamir and Zohar 1991; Pinxten et al. 2016). When students were asked to provide a mechanistic explanation for physiological or ethological phenomena,-comparable to their reasoning about evolutionary phenomena-the students tended to refer simply to the phenomena's functions rather than to elaborate on the underlying biological mechanisms. This teleological reasoning tendency distorts biological relationships between mechanisms and functions, and beyond that, has been argued to be closely related to the intentionality bias, a predisposition to assume an intentional agent, and even to creationist beliefs (Sinatra et al. 2008; Evans 2001). In biology education, teleological reasoning represents a profound problem that has been amply documented before instruction (Kampourakis and Zogza 2008, 2009; Jensen and Finley 1996; Pedersen and Halldén 1994; Settlage 1994; Stover and Mabry 2007), during instruction (Gresch and Martens 2019) and after instruction (Jensen and Finley 1996; Kampourakis and Zogza 2009; Pedersen and Halldén 1994; Settlage 1994; Stover and Mabry 2007; Jiménez-Aleixandre 1992).

To challenge students' teleological reasoning, it is necessary to understand its origins. Research in biology education has focused predominantly on the domaingeneral cognitive origin of students' teleological reasoning as described in cognitive psychology (Kelemen 2012; Coley and Tanner 2015; Kampourakis et al. 2012a, b; Opfer et al. 2012; Poling and Evans 2002; Stern et al. 2018). In cognitive psychology, people's intuitions are held accountable for teleological reasoning. Teleological intuitions are explained by so-called dual-process models, which distinguish between intuitive reasoning processes and reflective reasoning processes (Kelemen et al. 2013). Intuitive reasoning processes occur automatically, fast, effortlessly, and without voluntary control. Reflective reasoning processes require conscious attention and are often associated with comparatively slow and effortful mental activities. Whereas intuitive reasoning processes represent our default reasoning mode, reflective reasoning processes can override intuitive assumptions (Kelemen et al. 2013; Evans and Stanovich 2013; Kahneman 2012). Both, intuitive and reflective reasoning are context-sensitive and influenced by factors such as the cognitive capacities of people, and the particular domain in which the reasoning takes place (Evans and Stanovich 2013; Järvilehto 2015).
Much less attention has been paid to the domain-specific origin of students' teleological reasoning about biological phenomena. Notable exceptions are Keil (1992, 1995), Kampourakis (2013), and Abrams and Southerland (2001). Keil (1992, 1995), a cognitive psychologist, has proposed that the homeostatic organization of living beings might be a strong trigger for teleological reasoning. In particular, Keil $(1992,1995)$ has argued that the homeostatic organization of living beings is characterized by a causal interdependence among the parts of living beings and that people thus conceive of the parts of living beings as 'having purposes' that serve the living being as a whole. In biology education, Kampourakis (2013) has suggested that the concept of adaptive traits in biology might mislead students into inferring purpose and design in nature, if students lack information about the evolutionary mechanisms explaining how these traits came into being over time. Abrams and Southerland (2001) have argued that the curricular focus on 'why questions' about biological phenomena might mislead students into teleological reasoning. Relying on these authors, this paper argues that students' teleological reasoning in biology education not only has domain-general cognitive origins but also is triggered by domain-specific (biological) factors. The main line of argument is that the biological domain, in particular the concept of biological function, ${ }^{1}$ involves a notion of telos (in the sense of end or final state), which students might easily confuse with another notion of telos (in the sense of purpose, aim, or goal) that is inadequate if applied to the biological domain. The term telos has had a double meaning ever since Aristotle's work Physics, where Aristotle distinguished both meanings of telos (Koutroufinis 2016; Kullmann 1982; Löw

\footnotetext{
${ }^{1}$ The bio-philosophical discourse on the concept of biological function is characterized by two major approaches, system-analytic approaches and etiological approaches. This paper defines 'biological function' as "system-relevant effects of parts (or sub-processes) in systems of mutually dependent parts, i.e., those effects of any part that contribute to the maintenance of the other parts, and via them, feed back onto their own maintenance or perpetuation." (Toepfer 2012). This definition of biological function derives from a Kantian tradition and roughly corresponds with Cummins' (1975) system-analytic approach to function, which focuses on explicating the particular effect of a functional part or process. Etiological approaches (e.g. Wright (1973)), in contrast, focus on explicating the presence of a functional part or process (i.e. according to Wright (1973) "The function of X is Z means (a) X is there because it does $Z$, (b) Z is a consequence (or result) of X's being there.") The authors of this paper hold the opinion that system-analytic accounts and etiological accounts of function provide complementary insights into the concept of biological function (Walsh and Ariew 1999; Perlman 2009). For us as biology educators, both philosophical accounts of biological function can inform our reasoning about the challenges of teaching and learning about biological function. Whereas the etiological account of biological function has been a basis for educational theorizing before (Kampourakis 2013; Galli and Meinardi 2011), the system-analytic account has been largely neglected as a basis for educational theorizing about teaching and learning biological functions so far and thus provides the basis for discussion in the current paper.
} 
1980; Aristotle, trans. 2018; Toepfer 2004). ${ }^{2}$ To sort out misunderstandings, in this paper, we will further elaborate on the two different notions of telos.

It might seem paradoxical, at first, that the concept of biological function involves the notion of telos. After all, teleology has long been mainly discussed as a metaphysical concept in the philosophy of biology and as a learning obstacle in biology education, whereas biological function is considered a legitimate scientific concept and integral to biological thinking. However, at the time of the scientific revolution, scientists and philosophers, who aimed to demarcate science from metaphysics, were suspicious of not only teleology but also the concept of biological function (Perlman 2004). In fact, even today, biological function is a very unusual concept in the sciences and "sits uneasy within a naturalistic approach to the world" (Krohs and Kroes 2009, p 6). This uneasiness comes from the notion of end (telos) included in biological function. Biological functions "go beyond standard efficient causation" (Mossio et al. 2009, p 814) because they represent means-ends relationships (McLaughlin 2001). Whenever biologists attribute a function to a structure or mechanism, they consider the respective structure or mechanism as a means to an end. For example, biologists consider a heart a means to the end of pumping blood. Physicists, in contrast, would never consider a falling domino a means to the end of hitting another domino. Whereas physicists and chemists investigate cause-effect relationships without considering the effects as ends, biologists consider biological functions not merely as effects but as ends caused by some means (McLaughlin 2001).

Teloi in biology?-This idea might be alarming for biology educators, because their students tend to struggle with providing biological mechanisms and refer to goals instead. Consequently, educators aim to emphasize that biological mechanisms are not metaphysically directed towards goals. The concept of biological function still involves a specific notion of telos. This apparent

\footnotetext{
2 The double meaning of telos, however, has long been disregarded in later discussions of Aristotle's work. Krafft (1980), for example, argues that authors in the seventeenth and eighteenth century were not able to reconstruct Aristotle's position on teleology adequately and that the dominant natural-theological notion of teleology had superseded Aristotle's more subtle discussion of teleology. The distinction among the two different notions of telos were revived only with Kant at the end of the eighteenth century; Kant distinguished between 'inner purposiveness' and 'outer purposiveness' (Kant 1790). Hegel (1986) used the terms 'immanent teleology' and 'transcendent teleology', and Goudge (1961), Ayala $(1968,1970)$ and Lennox (1992) used the terms 'internal teleology' and 'external teleology' to distinguish two different notions of telos (Toepfer 2004). In this paper, we will use the terms 'epistemological teleology' and 'ontological teleology' in order to emphasize that only the latter notion of telos refers to actual goals that exist in nature, whereas the first notion of telos serves biologists as an epistemological tool to organize biological knowledge.
}

paradox can be resolved if one distinguishes between different understandings of telos, i.e., an ontological versus an epistemological understanding of telos. Ontology, the study of being, is concerned with identifying things that exist in the world. Epistemology, the study of knowledge, is concerned with the methods of acquiring knowledge of the things that exist in the world. An ontological use of telos in biological contexts is based on the assumption that teloi do in fact exist in nature and that natural mechanisms are directed towards teloi. An epistemological use of telos in biological contexts, however, applies the notion of telos as a methodological tool to structure biological knowledge. Further details on the epistemological use of telos will be given in the course of the paper. First, it is important to note that the postulated connotations of the concept of biological function are teleological in an epistemological sense rather than in an ontological sense. To distinguish clearly between the epistemological and ontological uses of telos, Pittendrigh (1958) suggested using the label teleology only to refer to ontological uses of telos, and he introduced the neologism teleonomy to refer to epistemological uses of telos. Such a terminological distinction has its merits by emphasizing the differences between adequate and inadequate uses of telos. ${ }^{3}$ Other philosophical traditions, however, emphasize the conceptual overlap between ontological and epistemological teleology by using the label teleological in connection with both notions of telos (Toepfer 2012; Perlman 2004; Illetterati and Michelini 2008; Griffiths 1993; Wright 1976). The present paper distinguishes between epistemological teleology and ontological teleology to highlight the notion of telos as conceptual overlap. The conceptual overlap is of interest to this paper because the notion of telos involved in the concept of biological function might prompt students to overgeneralize this notion to a wider range of biological phenomena without paying sufficient attention to the adequacy of these generalizations.

The following paragraphs provide further details concerning the distinction between ontological teleology and epistemological teleology. Furthermore, the paper draws practical implications on how to prevent students from slipping from adequate epistemological-teleological

\footnotetext{
${ }^{3}$ Given that the teleonomy-teleology distinction acquits biology from the reproach of applying inadequate metaphysical teleological notions, biologists are generally in favour of the teleology-teleonomy distinction (as for example Huxley (1960), Mayr (1961) and Lorenz (1973)). Some philosophers of biology, however, have criticized Pittendrigh's (1958) attempt to distinguish inadequate teleological notions from adequate biological teleological notions for remaining on the terminological level and for putting an end to discussions on teleological notions in the biological domain because Pittendrigh did not answer the more fundamental question of why biology includes references to teloi and how these are meant to be interpreted (Toepfer 2004; Illetterati and Michelini 2008; Krohs 2007; Lennox 1994).
} 


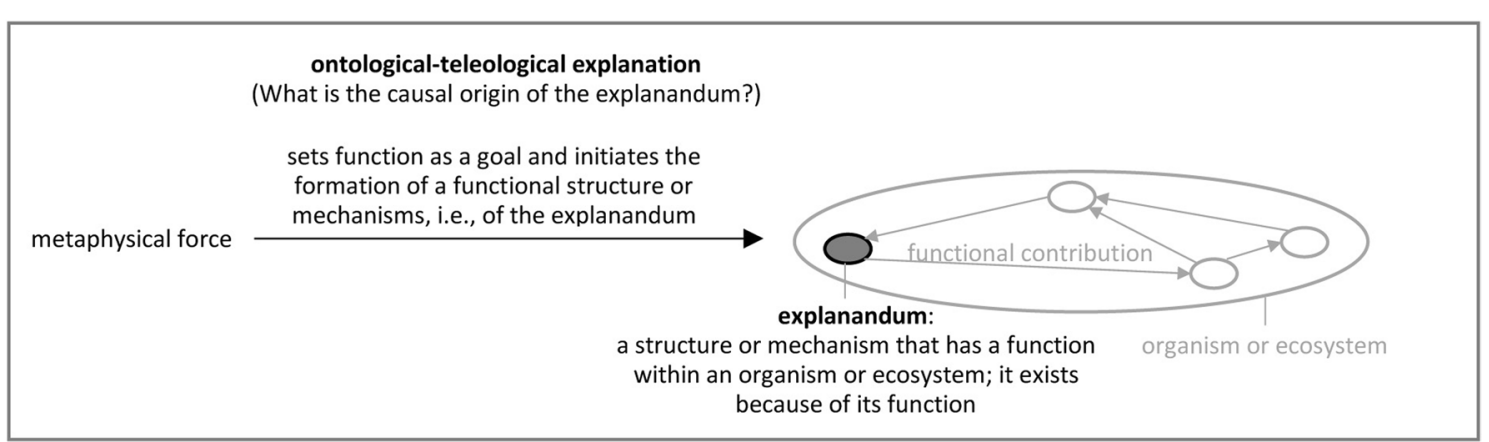

Fig. 1 A schematic representation of the concept of ontological teleology. Ontological teleology explains the causal history of an explanandum (small dark grey circle), which is a structure or mechanism that has a function within an organism or ecosystem (bigger light grey circle). The small light grey circles represent other structures or mechanisms within the organism or ecosystem to which the explanandum makes a functional contribution (the functional contribution is represented by the grey arrows). Ontological teleology assumes that an explanandum came into existence because of its function within the organism or ecosystem. Some instances of ontological teleology do not specify how exactly the formation of the explanandum became directed towards the function, but other instances of ontological teleology attribute the striving towards function to the intention of a force that sets functionality as a goal

reasoning into inadequate ontological-teleological reasoning. Finally, building on the distinction between epistemological and ontological teleology, the paper describes perspectives for future research.

\section{Ontological teleology}

The term ontological teleology refers to the assumption that functional structures and mechanisms exist due to their functionality (Fig. 1). From the perspective of ontological teleology, hearts in vertebrates, for example, came into existence simply because they fulfil the function of pumping blood. From a modern scientific point of view, such an ontological-teleological perspective on living phenomena is metaphysical and unscientific (Toepfer 2004; Illetterati and Michelini 2008; Neander 1991). One of the previous major arguments against ontological teleology is that functions, which can be observed in the present, cannot affect mechanisms in the past. From today's perspective, however, such an interpretation of ontological teleology as inverse causality came from scholastic teleology critics, not from the advocates of ontological teleology (Toepfer 2004; Krohs 2007). The advocates of an ontological teleology rather assumed that an organism-internal force (Bergson 1907; Driesch 1928) or an organism-external God (Paley 1819; Plato, trans. 1959) steered biological mechanisms towards function. These assumptions are analogous to human intentional action, where people set themselves goals and intend to realize them. A student thinks, for example, that he or she wishes to pass an exam and thus works towards that goal. In the field of biology, however, the hypothesis that goal-directed factors such as metaphysical forces exist cannot be verified empirically and is thus scientifically untenable.

Students' inadequate teleological reasoning, as documented in the biology education literature, can mostly be described as ontological-teleological reasoning. Some studies report that students simply state that a specific biological phenomenon occurred because it was believed to be functional, and the students do not specify how the phenomenon became directed towards the function (Abrams and Southerland 2001; Tamir and Zohar 1991; Michael 1998; Pinxten et al. 2016; Nehm and Ridgway 2011; Kampourakis et al. 2012a, b; Bartov 1978). Many instances of students' teleological reasoning might well constitute spontaneous ad hoc explanations, and the students might not have even thought about how exactly a phenomenon became directed towards its function. Other studies, however, have documented more elaborated types of teleological reasoning, where the students assumed that God, Mother Nature, an internal body wisdom, or an organism's intention set the purpose (Kampourakis and Zogza 2008; Kelemen 2012; Baalmann et al. 2004; Deadman and Kelly 1978; Halldén 1988; Kelemen and DiYanni 2005; Moore et al. 2002; Weitzel 2006). Halls et al. (2018), however, have provided evidence that not all students who reason teleologically believe that functional structures and mechanisms exist due to their functionality but rather discuss functional structures and mechanisms in terms of their benefit for an organism. Such a descriptive rather than causal use of teleological reasoning can be classified as epistemological teleology, which we will describe in the following paragraphs. 


\section{Epistemological teleology}

The notion of telos serves biologists as an epistemological tool for organizing the research field life and living organisms so that the phenomenon of life is not only at the core of the biological domain but also at the core of the teleology debate in biology (Toepfer 2012; Toepfer 2004). This insight goes back at least to Immanuel Kant's epistemology of living beings (Toepfer 2012; Ginsborg 2006). In his Critique of Teleological Judgment, the second part of his book Critique of Judgement (1790/93), Kant is concerned with the question of to what extent it is legitimate to reason about life in teleological terms (Ginsborg 2006). Kant grounds teleological reasoning in the life sciences on the specific causal structure of organisms, which scientists can (and, according to Kant, also need to) view through a teleological lens (Toepfer 2004, 2012; Quarfood 2006). We will first clarify what is so specific about the causal structure of organisms, and then, we will elaborate on the extent to which this causal structure can be viewed through a teleological lens. Specific about the causal structure of organisms is their cyclical organization. In an organism, each structure participates in producing other structures, and eventually, via the production of other structures, each structure contributes to its own reproduction (or at least to the production of its own types). Thus, each structure is the cause and effect of itself (Toepfer 2012). Figure 2 visualizes this causal interdependence among organismic structures.

To what extent does the cyclical causal structure of organisms legitimize a teleological perspective on organisms? Although, ontologically, a causal cycle has neither a start nor end point, epistemologically, the perceiver can stipulate a certain point as the end and consider structures and mechanisms that contribute to the stipulated end as means to that end (Toepfer 2012).

In the teleology debate, it is important to emphasize that biologists who apply a teleological perspective do

\footnotetext{
${ }^{4}$ We have repeatedly mentioned in this paper that real teloi do not exist in nature, but that biologists use the telos concept as an epistemological tool. If we assume an epistemological rather than an ontological telos concept, does that mean that we view the concept of biological function merely as a subjectively imagined concept or as a real object in nature? This question has been approached by two opposing positions. Representatives of the first position have argued that function attributions would principally say less about reality than about the human mind (Baublys 1975; Prior 1985; Ratcliffe 2000; Searle 1995). In line with representatives of the second position (Toepfer 2004; Grünewald 1996; Jacobs 1986), we argue that biological functions do have ontological relevance. Toepfer (2004) argues, and we follow him in this respect, that Kant's epistemological approach does not merely clarify the structure of our minds, but also the conditions of knowledge of the objects of our experience. In other words, Kant's epistemological tools are associated with ontological features of the object.

Yet other philosophical positions define the concept of biological function as a purely objective property without any epistemological reference point. Instead of an epistemological telos, such approaches have proposed the concepts of autopoiesis (i.e. an der Heiden et al. 1985, Varela et al. 1974), plasticity (i.e. Braithwaite 1946), and persistence (i.e. Rosenblueth et al. 1943, Sommerhoff 1950). Autopoiesis refers to the self-maintaining and self-
}

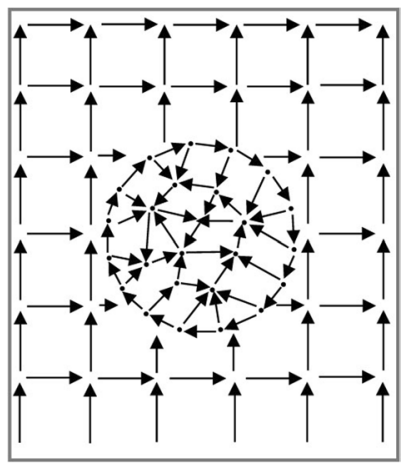

Fig. 2 Representation of the interdependence of organismic structures and mechanisms within the cyclical causal structure of an organism (modified after Toepfer (2012))

not assume that ends exist in nature. Rather, they conceptualize a structure or mechanism epistemologically as a means to a future effect within an organism. ${ }^{4}$ For example, from the perspective of epistemological teleology, biologists analyze the heart in terms of its effect as a tool for pumping blood. This means-ends analysis is also evident in the word organ, which is derived from Greek órganon and means instrument, tool. Such an epistemological-teleological perspective does not conflict with a causal explanation of the physiology, ontogeny, or evolution of the heart. The epistemological-teleological perspective differs from a causal perspective not in terms of the assumed temporal relations between cause and effect but in terms of its epistemic conceptualization. Notably, conceptualizing structures and mechanisms in terms of their ends does not explain biological structures and mechanisms in terms of their causes but identifies ${ }^{5}$ them in terms of their effects (Toepfer 2004, 2012; Quarfood 2006). In the following paragraphs, we will explicate how

\footnotetext{
Footnote 4 (continued)

organizing characteristic of organisms. Plasticity describes the characteristic of "attain[ing] the same goal under different circumstances" (Braithwaite 1946, p 329), and persistence refers to the characteristic of maintaining and pursuing internal states. In accordance with Toepfer (2004), we argue that our cognition of an autopoietic, plastic, or persistent system is also the result of an epistemologically teleological schematization of causal processes. As we describe an autopoietic, plastic, or persistent system, we relate mechanisms to each other, which we could also describe individually or in different relations. The relational description of these mechanisms is thus an epistemological construct. The features of autopoiesis, plasticity, and persistence are features of a system that depend on a preceding conception of that system. At the same time, an empirically justified use of these concepts is rooted in empirical knowledge. Whereas many approaches that rely on the concepts of autopoiesis, plasticity, and persistence have not referred to their epistemological a priori assumptions, more recent accounts that conceptualize biological function as an objective property of an organism, clearly explicate their preceding epistemological references (i.e. van Hateren 2017; Weber 2017).

5 'identify' is used in the sense of 'determine characteristic attributes'.
} 


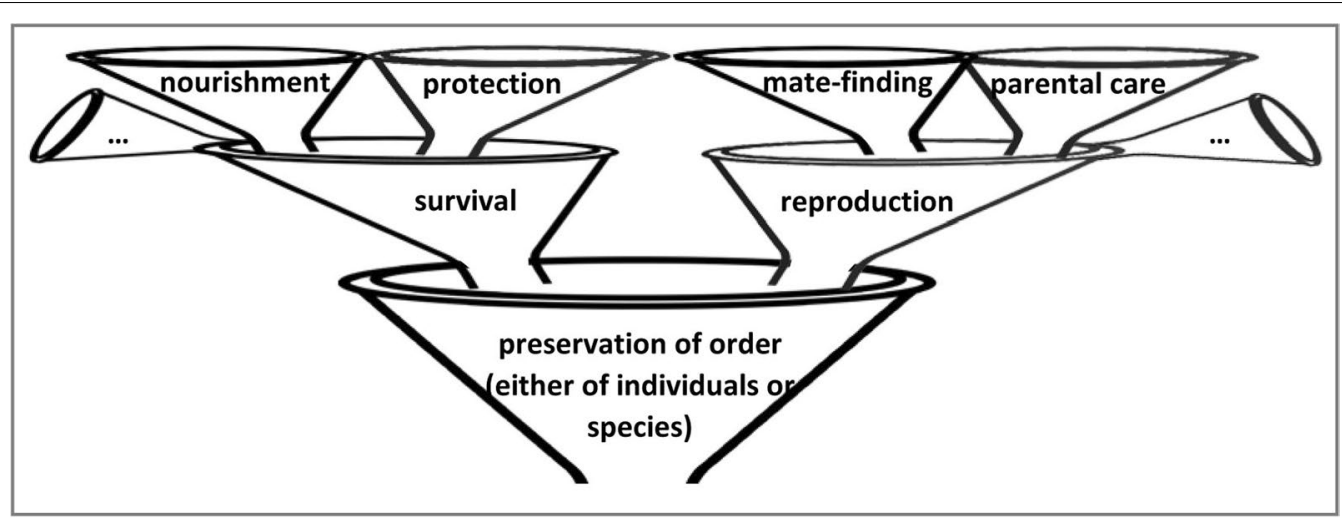

Fig. 3 The hierarchy of biological function. At the top of biological function references stand the functions of survival and reproduction. These two functions qualify as top functions as both preserve an order structure, i.e., either the individual or the species. Any other biological function serves either survival or reproduction (modified after Toepfer (2011))

biologists identify biological phenomena with reference to ends. Subsequently, we will illustrate how the epistemological-teleological identification of phenomena relates to their mechanistic explanations.

Understanding structure-function relationships and mechanism-function relationships are major goals in the field of biology. In epistemological-teleological identifications, biologists relate structures or mechanisms to one of the two ends of survival and reproduction (Toepfer 2004). Biologists, of course, do not assume that survival and reproduction are ends inherent in nature. Rather, biologists use survival and reproduction as epistemological reference points when attributing functions to structures and mechanisms. Survival and reproduction are ideal as epistemological reference points because both notions preserve the structure of an order. Survival preserves the order of an individual organism, and reproduction preserves the order of a species (Toepfer 2011). Survival and reproduction represent the top of the hierarchy of biological function (McLaughlin 2001) (Fig. 3). For example, the concentration of calcium ions in heart cells serves the end of the contraction of the heart. The contraction of the heart, in turn, serves the end of the circulation of the blood, which eventually serves the end of the survival of the organism. Also, in the case of the peacock's fan, biologists posit the end of finding a mate, which can in turn be conceptualized as a means to the end of reproduction. Additionally, identifying a specific gene necessitates an epistemological reference to a protein as its end, which in turn serves as a means to the end of survival or reproduction (Hornbergs-Schwetzel 2012). Eventually, biologists stop the regress of means-ends analyses at one of the two major ends (teloi), survival and reproduction (McLaughlin 2001). The epistemological reference of means to ends is fundamental to the concept of biological function. Whenever biologists argue that a biological structure or mechanism is functional, they judge it as a means in relation to an end (McLaughlin 2001), which will be exemplified in the next paragraphsfirst for biological structures and then for biological mechanisms.

Biologists identify an individual biological structure in two different ways: in terms of its material composition and in terms of its effect as a means to realize the capacities of the whole organism. For example, gastric juices can be identified in terms of their material composition as consisting of hydrochloric acid, potassium chloride, and sodium chloride and in terms of their effect as a means to digestion. Whereas the identification in terms of the material composition is also used to identify inorganic structures such as stones, the identification in terms of the effect is characteristic of biological structures. Identifying structures in terms of their effects is possible in biology because biological structures are integrated into the cyclical causal organization of organisms: each structure causally contributes to other structures, and each structure, in turn, is supported by them. For example, the heart, kidneys, and stomach are parts of the organism that support each other, as each part contributes in its own way to survival: the heart to circulation, the kidneys to excretion, and the stomach to nourishment. Thus, a particular biological structure such as the heart can be defined not only in terms of its material composition but particularly in terms of its contribution to the whole organism. The biological practice of identifying biological structures as means to ends is reflected in the functionalist concept formation of the biological domain (Toepfer 2004, 2008; Beckner 1968). In biology, structures are often named in terms of their effects, as for 


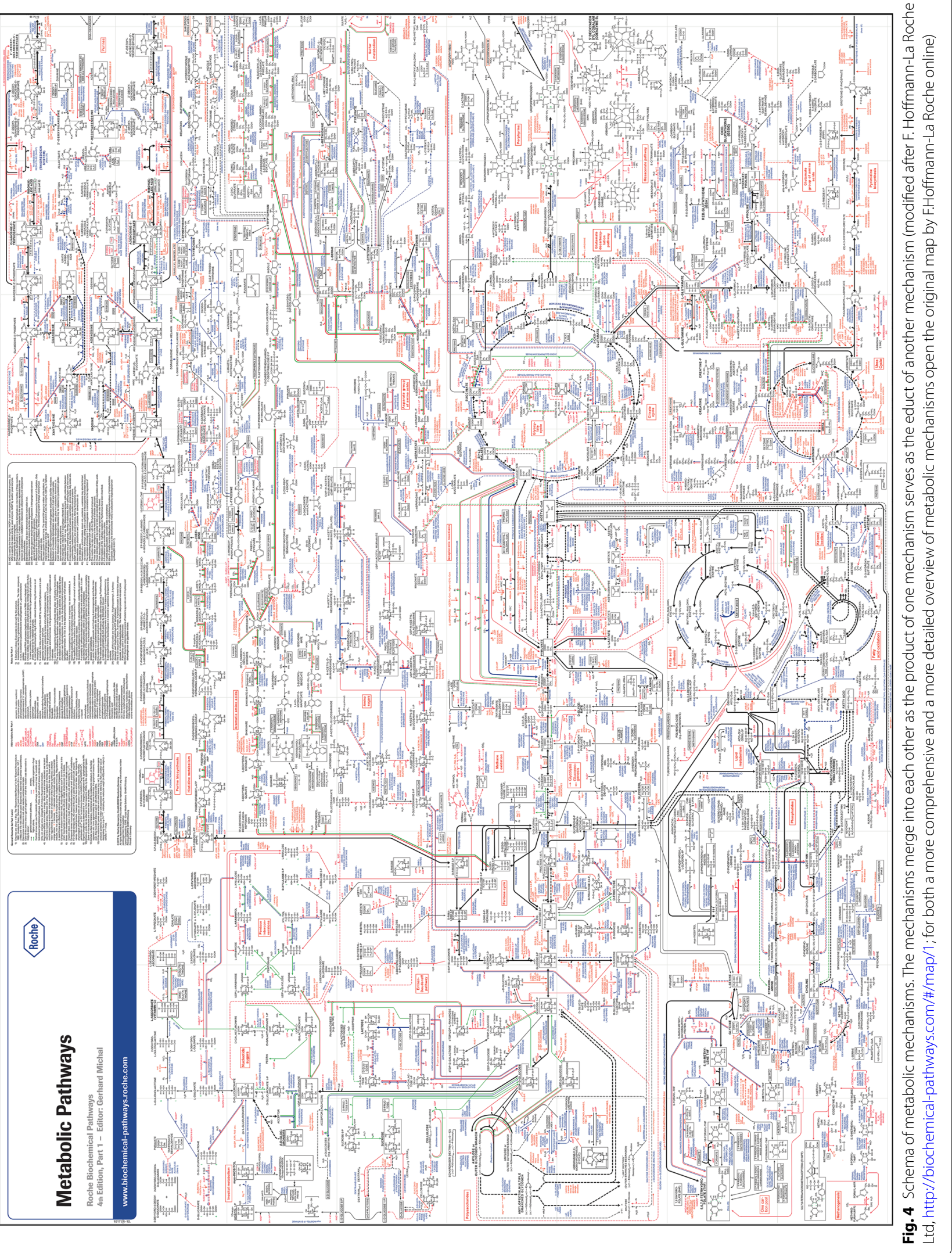




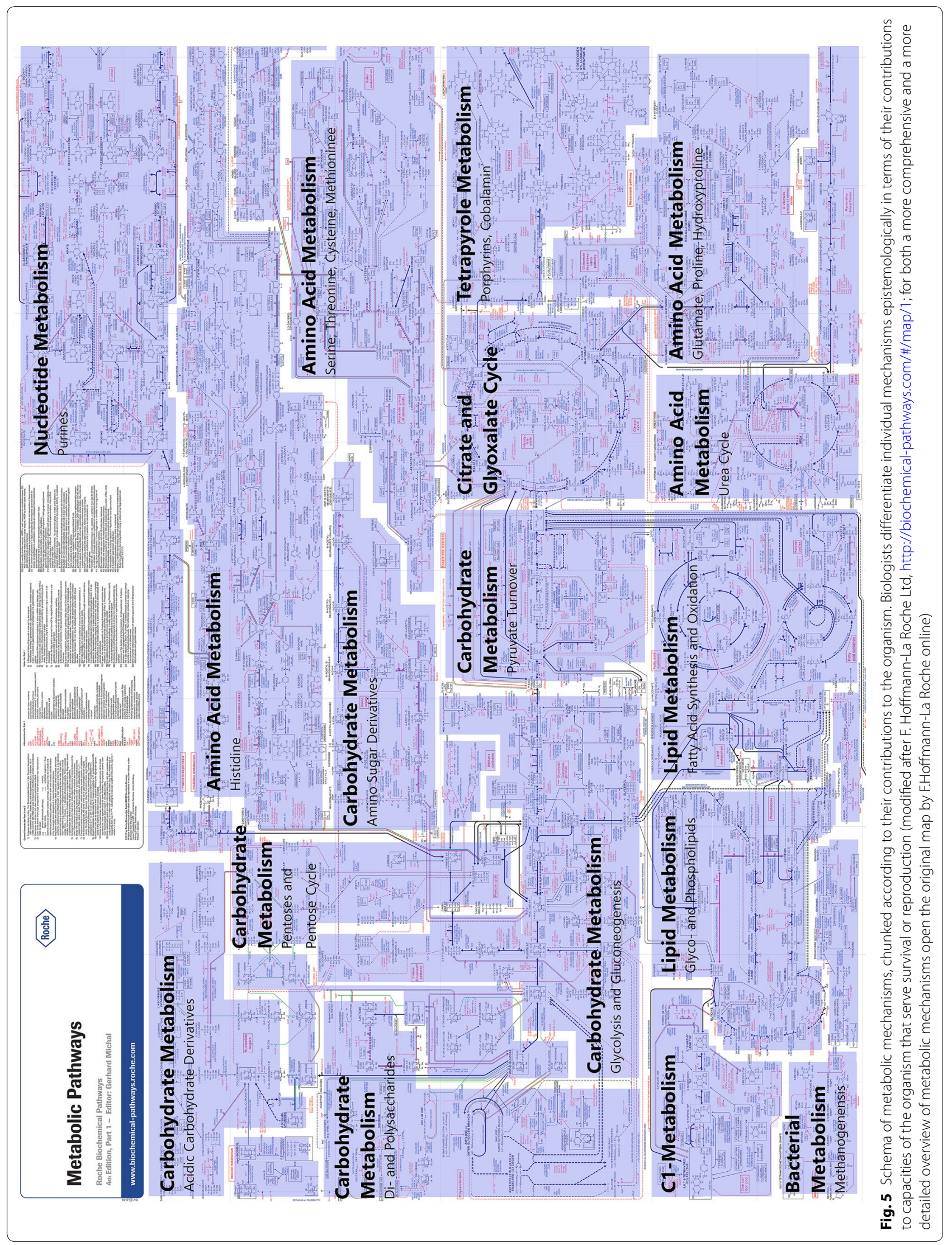




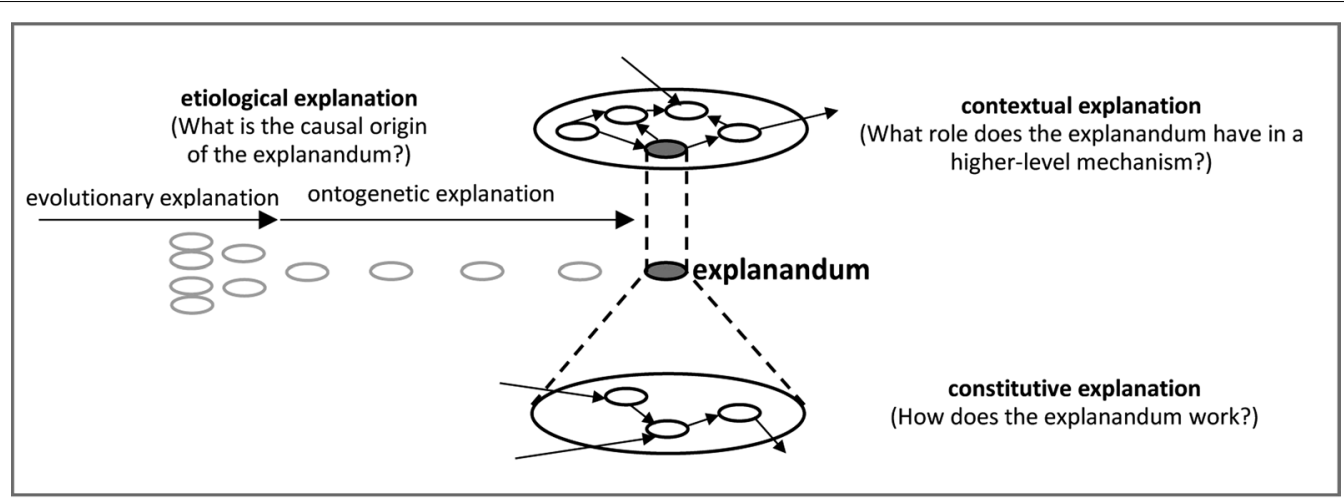

Fig. 6 Representation of the multiplicity of explanatory perspectives on an organismic entity in biology according to the mechanistic philosophy of Craver. Etiological explanations, constitutive explanations, and contextual explanations answer different research questions and complement each other. Etiological and constitutive explanations take a mechanistic perspective, and contextual explanations take a teleological perspective on the explanandum. For the sake of clarity, the etiological explanations are represented at only one level of biological organization, although they also involve higher and lower levels (modified after Craver (2013))

example gastric juices, $t$-helper cells, incisors, or nutritive tissue (Krohs 2004, 2014; Weber and Varela 2008).

Biologists apply means-ends analyses not only to identify biological structures but also to identify biological mechanisms. Without means-ends analyses, biologists would be confronted with an overwhelming complexity of merging mechanisms (Toepfer 2004). Figure 4 illustrates the complexity of merging mechanisms using the example of metabolic pathways. To structure the ontological complexity and to develop tangible research foci, biologists differentiate individual mechanisms through epistemological considerations, that is, by assuming idealized starting and termination conditions (Machamer et al. 2000). In determining the idealized termination conditions, teleological considerations play a significant role because "the termination conditions are most often idealized as end points or final products (Machamer et al. 2000, p 12) [emphasis added]." The epistemological purpose of applying a teleological perspective to distinguish between one mechanism and another is illustrated in Fig. 5. Figure 5 shows the same mechanisms as Fig. 4, but Fig. 5 additionally portrays the epistemological delimitations between individual mechanisms. For instance, Fig. 5 individuates glycolysis and gluconeogenesis as aspects of carbohydrate metabolism. As indicated by the terms, the glycolysis mechanism [glycose is an older term for glucose, Greek lysis=degradation] serves to break down glucose, whereas the gluconeogenesis mechanism [gluco stands for glucose, Greek neos = new, Greek genesis $=$ creation] serves to synthesize glucose from noncarbohydrate carbon compounds. The two mechanisms, like other biological mechanisms, are chunked according to their contribution to the organism. Biologists often perform such chunking processes in relation to a normatively posited end (telos) (Craver 2013). Craver (2013), one of the major representatives of a mechanistic philosophy, thus states that 'Mechanistic descriptions [thus] come loaded with teleological [Craver refers to epistemological, not ontological teleology] content.'

Identifying biological structures and mechanisms from the perspective of epistemological teleology is complementary to explaining them mechanistically. In fact, a biological phenomenon can be fully understood only if one identifies it epistemologically-teleologically and explains it mechanistically (Toepfer 2004; Craver 2013). This relationship represents a fundamental difference from ontological-teleological explanations, which are not complementary to mechanistic explanations but compete with them. Figure 6 illustrates the relationship between epistemological-teleological identifications and mechanistic explanations. In its center, the figure displays the explanandum, i.e., the structure or mechanism to be explained, as for example gastric juices or the glycolysis mechanism. Identifying the explanandum is a necessary starting point for any explanation, which often involves relating the explanandum to the end it serves. Following Craver (2013), one can distinguish three different ways of situating the teleologically identified explanandum in the causal structure of the world, namely, etiological explanations, constitutive explanations, and contextual explanations. Each of the three explanation types answers a different question about the explanandum. Whereas etiological and constitutive explanations provide mechanistic information on the explanandum, constitutive explanations provide epistemological-teleological information. To explain an explanandum as comprehensively as possible, all three explanatory perspectives are needed. The 
following three paragraphs further explain these three types of explanation.

Etiological explanations are illustrated in Fig. 6. As shown on the left side of the figure, etiological explanations are backward-looking, as they are given in response to questions about the origin of the explanandum. Typical questions about the origin of biological structures or mechanisms concern the evolutionary and ontogenetic history of a phenomenon. For example, taking an organism's heart as the structure to be explained, its evolutionary history can be traced back to simple tubular hearts. From generation to generation, existing elements were modified, and new elements were added throughout a continuous selection process of the fittest individual organisms within populations (see Olson (2006) for further details on the evolution of hearts). In addition to its evolutionary history, the heart can also be explained in terms of its ontogenetic history: During ontogeny, the structure of the heart originates from the interplay of DNA, RNA, proteins (Chen and Fishman 2000; Srivastava and Olson 2000), biochemical gradients (Raya et al. 2004), voltage gradients (Levin et al. 2002), and fluid mechanical stimuli (Hove et al. 2003).

Constitutive explanations are illustrated by the circle at the bottom of Fig. 6. The figure shows that constitutive explanations are downward-looking towards lower-level activities and entities that produce the explanandum. Constitutive explanations are given in response to questions about how an explanandum works, and they elaborate on physiological mechanisms. For example, the pumping action of the heart can be explained by contractions of the cardiac muscle fibers. From the contracting cardiac muscle fibers, one could potentially look a further level down to the molecular mechanism involving calcium ions, tropomyosin, actin, and myosin.

Contextual explanations are illustrated by the circle at the top of Fig. 6. The figure shows that contextual explanations are upward-looking towards a higher-level mechanism, and they explain what the phenomenon does as a part of that higher-level mechanism. Contextual explanations are given in response to questions about the role of the explanandum within higher-level mechanisms and within an organism. There is no sharp distinction between a contextual explanation and a teleological identification of an explanandum. Where one draws the demarcation line is essentially an epistemological decision (Craver 2013). A contextual explanation for the pumping action of the heart focuses on the heart's expulsion of blood, which in turn provides the circulatory system with blood. If one wanted to give a more comprehensive contextual explanation, one could refer to the subsequent distribution of oxygen and nutrients through the body.
Craver's framework involving three explanatory perspectives sheds some light on the teleology debate, which has long been fraught with misunderstandings on whether the biological domain includes the notion of end (telos). On the one hand, by recognizing the etiological and constitutive explanations, Craver's framework makes it abundantly clear that the biological domain is based on mechanisms that are not directed towards ends. On the other hand, by recognizing that the contextual explanation refers to higher-level ends, Craver's framework stipulates that the biological domain uses the notion of end as a reference point that is not in conflict with biological mechanism. Moreover, by assigning each type of explanation a particular reasoning direction (i.e., backward, downward, upward), Craver makes it clear that the explanandum is one and the same, although each type of explanation answers a different question about the explanandum from its particular perspective.

\section{The fine line between ontological and epistemological teleology in biology education}

The perspective of epistemological teleology is an implicit aspect of the concept of biological function not only in biology but also in biology education. If one says that the function of a plant's growing towards the light is to absorb sunlight, one conceptualizes this function as a means to the end of absorbing sunlight. Similarly, if one argues that the function of resistance to a pesticide is to help organisms survive, one conceptualizes resistance as a means to the end of survival. Whereas for biologists such means-ends analyses represent a productive tool for identifying biological structures and mechanisms, for students such means-ends analyses can be misleading. The epistemological expectation that biological phenomena function and exist for survival is close to the ontological assumption that biological phenomena came into existence for functioning and maintaining survival. Thus, in biology education, students may slip from the epistemological teleology inherent in biological function to ontological assumptions about biological mechanisms.

The danger of slipping from an epistemological-teleological assumption to ontological assumptions is aggravated by the fact that biological questions often revolve around functional phenomena, that is, epistemological-teleological phenomena. For example, if students are asked "How does it happen that plants grow towards light?" (Abrams and Southerland 2001) or "How would biologists explain how a living bed bug species with resistance to a pesticide evolved from an ancestral bed bug species that lacked resistance to the same pesticide?" (Nehm et al. 2012), the questions introduce functional phenomena from the perspective of epistemological 
teleology, even if they aim at a mechanistic explanation. In the case of the question about the plant's bending towards light, students view the phenomenon at first teleologically as a functional phenomenon for the whole organism. To explain the constitutive mechanism as a second step, they must apply the downward-looking mechanistic perspective. In the case of the question about the evolution of the resistance to a pesticide, students view the phenomenon at first teleologically as a functional phenomenon for the whole organism. To explain the etiological mechanism as a second step, they must apply the backward-looking mechanistic perspective. Thus, answering mechanistic questions about the causal origins of biological phenomena requires students to change their reasoning perspective from the teleological identification of the phenomenon to its mechanistic explanation.

Given that the biological domain includes means-ends analyses, students could be particularly susceptible to rely on their intuitive teleological predispositions when they reason about biological phenomena. In biology education, students need to use means-ends reasoning reflectively rather than intuitively and make the conscious decision to apply means-ends reasoning to identify functional relations rather than to explain causal origins.

\section{Educational recommendations}

The notion of telos (end, final state) involved in biological function is potentially misleading for students. Whereas biologists use the notion of telos for epistemological purposes, students tend to think that nature is ontologically directed towards teloi. To prevent students from slipping from the epistemological teleology involved in biological function into ontological teleology, two main learning goals are essential. First, biology educators should enable students to distinguish between biological functions and biological mechanisms. Second, biology educators should enable students to explain that nature is not directed towards goals.

\section{Learning goal 1: Distinguishing between biological functions and biological mechanisms}

The first learning goal addresses the relationship between functions and mechanisms in biology. Its implementation requires-as trivial as it might seem-addressing both the functions and mechanisms of explananda in biology education. At the moment, however, biology curricula tend to focus more on functional 'why' questions than on mechanistic 'how' questions (Abrams and Southerland 2001). Especially in younger school years, the curricula focus students mostly on structure-function relationships, whereas the constitutive mechanisms are mostly absent in classes on human biology as well as in classes on plant and animal physiology. Only towards the end of students' school careers do curricula introduce evolutionary mechanisms (Ministry of Education and Training of the State of North Rhine-Westphalia 2008; Saxon State Ministry of Education and Sports 2011). Thus, it is unrealistic to expect students to be competent in providing mechanistic explanations. Indeed, students have been documented to struggle with mechanistic explanations and to provide functions rather than mechanisms in response to questions about mechanisms (Abrams and Southerland 2001). For example, students explained the ability of plants to grow towards light by referring to the functional aspect that plants need light for photosynthesis. It goes without saying that the students' struggle with mechanisms cannot be resolved by teaching every single mechanism, such as the complex mechanism of phototaxis. This attempt would overload the curricula. However, students need to be familiar with mechanistic explanations as an important explanation type in biology. Furthermore, students must become aware of the domain-specific principle that references to mechanisms and functions approach an explanandum from different perspectives. To illustrate to students how references to mechanisms and functions contribute to explaining an explanandum, we recommend explicit discussions of the explanatory perspectives in biology education by using a range of different exemplary cases. Exemplary cases are important when teaching such abstract meta-knowledge about the explanatory perspectives in biology because students need to apply abstract knowledge in connection with concrete examples to fully understand a topic (Zohar and David 2008). Such meta-level discussions of the explanatory perspectives in biology are not currently common in biology education but have been recommended (Pinxten et al. 2016). Decisive for teaching practice is the message that we need to investigate all explanatory perspectives to explain a phenomenon comprehensively and that we must always have a clear idea of which explanatory perspective answers which question. In this paper, we summarized Craver's (2013) explanatory perspectives, which can become a framework for explaining biological phenomena. This framework might be beneficial for reducing students' inadequate teleological reasoning, as it clearly shows that means-ends reasoning is appropriate only in contextual explanations but not in etiological or constitutive explanations. In the future, research is necessary to investigate which cases are ideally suited for integrating the different explanatory perspectives.

\section{Learning goal 2: Explaining that nature is not directed towards ends}

Research on students' inadequate teleological conceptions has shown that they often coexist with adequate 
scientific concepts. Thus, teaching adequate scientific concepts alone does not suffice for changing students' teleological conceptions, but in addition, students' inadequate teleological conceptions must be explicitly addressed (Kampourakis and Zogza 2009; Nehm et al. 2012; Alters 2005). Students should not only be able to explain scientific concepts but should also be able to explicate that nature is not directed towards teloi. We suggest focusing instruction on the guiding question 'Are there goals in biology?' to elicit students' inadequate teleological preconceptions, to discuss the preconceptions with students, and to foster students' ability to distinguish between the two notions of telos discussed in this paper: the adequate notion of telos as a descriptive tool versus the inadequate notion of telos as a goal towards which biological mechanism are directed. Biologists describe parts of an organism in terms of their contribution to the 'ends' of survival and reproduction. This description helps biologists to describe the internal organization of organisms. However, biology instruction needs to make it clear that the self-organization of organisms does not involve any teleological forces but rather non-teleological cause-effect relationships.

Such attempts can build on teaching suggestions that aim to show students that biological mechanisms are not goal-directed. For example, Kampourakis and Zogza (2009) described an approach that involved demonstrating why evolution is incompatible with goals in nature by emphasizing the role of chance and unpredictability in evolution. In particular, the authors used an activity that highlighted that several important events in evolution are unpredictable rather than goal-directed: (a) the origin of genetic variation within populations, (b) the fusing of gametes, (c) the migration of parts of a population to unoccupied niches, and (d) the environmental changes in an ecosystem (for the activity see Kampourakis (2006)). In another intervention study, Jensen and Finley (1996) focused students on the question of whether evolution is goal-directed by discussing historically rich materials, which succeeded in reducing students' teleological reasoning more effectively than a traditional teaching approach in a control group.

In addition to the intervention approaches mentioned above, we suggest discussing the question 'Are there goals in biology?' in connection with the topic 'the evolution of life on earth'. Discussing the phenomenon of life would address the core of the teleology problem in biology because life, i.e., any living organism, is characterized by a 'purposive' organization in the sense that the structures and mechanisms within a living organism are means to the 'ends' of survival or reproduction. For students, the fact that almost every structure and mechanism within an organism contributes to the organisms' survival or reproduction can give the impression that nature is directed towards survival and reproduction. Students thus need a satisfying non-teleological explanation for how this 'purposive' organization of organisms came into existence. Merely discussing evolutionary explanations for isolated functional structures, such as the giraffe's long neck or the polar bear's white fur, might not give a fully satisfying answer to students on how the 'purposive' organization of living beings came into existence, as evolutionary explanations that concern isolated functional structures focus merely on the transformation of this particular structure and already presuppose living and thus self-organized ancestors. By addressing how life on earth evolved, students can see that the means-ends relations that typically exist among the parts of a living organism and the whole living organism came into existence as the result of mechanistic processes rather than teleological forces.

Working towards the goal of students being able to explicate that nature is not directed towards teloi requires the development and testing of further materials that stimulate discussions about goals in biology and provide counter-evidence to inadequate teleological assumptions. Merely avoiding teleological language, as has been suggested in the biology education literature (Hughes 1973), overlooks the complexity of the problem by failing to distinguish between adequate epistemological and inadequate ontological teleology. The issue is problematic because both types of teleology, epistemological teleology and ontological teleology, refer to means-ends relationships and express them using teleological language. The ambiguity of teleological language should be explicitly discussed in biology education rather than ignored (Trommler et al. 2018; Galli and Meinardi 2011; Zohar and Ginossar 1998). After all, students encounter teleological language in out-of-school contexts such as wildlife documentaries, science museums, or biology books (Zohar and Ginossar 1998; Aldridge and Dingwall 2003; Sealey and Oakley 2014) and should be aware of the difference between adequate epistemological interpretations and inadequate ontological interpretations of teleological language. Discussing biologically incorrect student statements in comparison to authentic statements by biologist and statements from popular biology is a promising strategy to familiarize students with different shades of meanings of the notions of 'end' and 'goal.' This strategy involves students explicating that biologists always use terms such as 'functional', 'useful', 'necessary', 'serving', or 'being for' in a relational sense, i.e., in relation to the functioning of a higher organismic level or the whole organism, but not to express nature-inherent values. For example, if biologists say "The hummingbird [...] has a long bill to feed on the nectar of flowers." (Matsunaga 
and Okanoya 2009, p 360) they describe the contribution of the bill to the hummingbird's nutrition. Using Craver's schema, teachers and students can gain the insight that biologists take an upward perspective when they explain the long bill of the hummingbird teleologically but do not answer any downward or backward-looking questions.

\section{Future research}

Future research needs to examine the effectiveness of the educational recommendations suggested in this paper in terms of improving students' ability to avoid inadequate teleological reasoning. Furthermore, the recommendations made in this paper require further research activities focused on assessing how biological functions and mechanisms are represented in biology instruction. Additionally, the recommendations require discussing and developing curricula in terms of content and sequence and comprehensively developing apt materials on the scope and limit of biological functions, their relationship to biological mechanisms, and their differences from metaphysical goals. Moreover, the distinction between epistemological and ontological teleology presented in this paper can inform attempts to improve the accuracy of assessing students' teleological reasoning. So-called explanation judgment tasks, for example, ask students for acceptance judgments and preference judgments in favor of either teleological or mechanistic explanations (Coley and Tanner 2015; Kelemen and DiYanni 2005; Kelemen 1999, 2003; Richardson 1990). This assessment format is based on the assumption that the preference for teleological explanations is indicative of inadequate ontologicalteleological reasoning. An interview study investigating students' reasons for preferring either mechanistic or teleological explanations, however, revealed that some students interpreted teleological explanations ontologically, whereas others interpreted them epistemologically (Trommler et al. 2018). Although some biology educators have reflected upon the nuances of teleological language and their relevance for teaching and testing, respective test instruments that can distinguish between adequate (epistemological) and inadequate (ontological) teleological conceptions are lacking (Trommler et al. 2018; Stern et al. 2018; Halls et al. 2018; Zohar and Ginossar 1998; Höst and Anward 2017). For developing such test instruments, meta-level tasks might be helpful, for example, tasks that require students to interpret teleological explanations and tasks that require visualizing causal relationships. Furthermore, for future research, we suggest applying the distinction between ontological and epistemological perspectives to other concepts, such as the species concept, the gene concept, and the concept of biological information. By making the epistemological implications of such concepts visible to students, educators could succeed in reducing their students' misconceptions about them.

\section{Conclusions}

Whenever biologists, biology teachers and biology students ascribe functions to biological structures or mechanisms, they consider them as means to an end. The means-ends relationship inherent in biological function has been largely neglected in biology education, probably because biology educators have prioritized demarcating biology from ontological teleology and have thus emphasized that ends do not belong to the biological domain. Considering the long history of the debate about teleology in the philosophy of biology as well as the prominence of students' teleological reasoning in biology in comparison to other school subjects, however, we revisited the question of whether ends belong to the biological domain. Based on current insights from the philosophy of biology, this paper distinguished two different understandings of telos: an ontological versus an epistemological understanding. The former is inadequate because of the assumption that ends and goals do in fact exist in nature and that natural mechanisms are directed towards goals. The latter, in contrast, is adequate insofar as it does not assume that ends and goals exist in nature. Rather, epistemological teleology centers around the idea that ends represent a methodological tool to structure biological knowledge. Epistemological means-ends considerations allow the contribution of organismic parts to survival or reproduction to be described. For biologists, such means-ends considerations are highly productive for describing living organisms. For students, in contrast, means-ends considerations can be misleading. The argument we put forth in this paper, thus, is based on the insight that an epistemological understanding of ends is a central aspect of the biological domain. As a major implication for biology instruction, students need to understand the scope and limits of epistemological means-ends considerations to refrain from slipping into inadequate ontological assumptions about ends. Craver's framework details multiple explanatory perspectives in biology. It is valuable for research and development focusing on the distinction between epistemological and ontological teleology to prevent students from confusing one with the other.

\section{Acknowledgements}

We thank Ulrich Krohs for substantive feedback on the philosophical aspects of this paper.

\section{Authors' contributions}

FT and $\mathrm{MH}$ conducted a literature review. FT conceptualized and wrote the manuscript. FT and $\mathrm{MH}$ discussed and revised the manuscript. Both authors read and approved the final manuscript. 


\section{Funding}

Not applicable.

\section{Availability of data and materials}

Data sharing not applicable to this article as no datasets were generated or analysed during the current study.

\section{Competing interests}

The authors declare that they have no competing interests.

Received: 26 October 2019 Accepted: 30 April 2020

Published online: 29 May 2020

\section{References}

Abrams E, Southerland S. The how's and why's of biological change: how learners neglect physical mechanisms in their search for meaning. IJSE. 2001;23:1271-81.

Aldridge M, Dingwall R. Teleology on television? Eur J Commun. 2003; 18:435-53.

Alters BJ. Teaching biological evolution in higher education: methodological, religious, and nonreligious issues. Sudbury: Jones and Bartlett Publishers; 2005.

an der Heiden U, Roth G, Schwegler H. Principles of self-generation and selfmaintenance. Acta Biotheor. 1985:34:125-38.

Aristotle (Phys. 194a). Reeve CDC. Physics. Cambridge: Hackett Publishing; 2018

Ayala FJ. Biology as an autonomous science. Am Sci. 1968;56:207-21.

Ayala FJ. Teleological explanations in evolutionary biology. Philos Sci. 1970;37:1-15.

Baalmann W, Frerichs V, Weitzel H, Gropengießer H, Kattmann U. Schülervorstellungen zu Prozessen der Anpassung-Ergebnisse einer Interviewstudie im Rahmen der didaktischen Rekonstruktion [Student conceptions on processes of adaptation - results of an interview study in the context of didactic reconstruction]. ZfDN. 2004;10:7-28.

Bartov H. Can students be taught to distinguish between teleological and causal explanations? J Res Sci Teach. 1978;15:567-72.

Baublys KK. Comments on some recent analyses of function statements in biology. Philos Sci. 1975:42:469-86.

Beckner M. The biological way of thought. Berkeley: University of California Press; 1968.

Bergson H. L'évolution créatrice [Creative evolution]. Paris: Presses Universitaires de France; 1907

Bishop BA, Anderson CW. Student conceptions of natural selection and its role in evolution. J Res Sci Teach. 1990:27:415-27.

Braithwaite RB. Causal and teleological explanation. In: Braithwaite RB, editor. Scientific explanation. A study of the function of theory, probability and law in science. Cambridge: Cambridge University Press; 1946. p. 319-41.

Chen J, Fishman MC. Genetics of heart development. Trends Genet. 2000:16:383-8.

Coley JD, Tanner K. Relations between intuitive biological thinking and biological misconceptions in biology majors and nonmajors. CBE Life Sci Educ. 2015;14:ar8

Craver CF. Functions and mechanisms: a perspectivalist view. In: Huneman P, editor. Functions: selection and mechanisms. Dordrecht: Springer; 2013. p. 133-58.

Cummins R. Functional analysis. J Philos. 1975;72:741-65.

Deadman JA, Kelly PJ. What do secondary school boys understand about evolution and heredity before they are taught the topics? J Biol Educ. 1978;12:7-15

Driesch H. Philosophie des Organischen [Philosophy of the organic]. Leipzig: Quelle \& Meyer; 1928

Evans EM. Cognitive and contextual factors in the emergence of diverse belief systems: creation versus evolution. Cogn Psychol. 2001;42:217-66.

Evans JSBT, Stanovich KE. Dual-process theories of higher cognition. Perspect Psychol Sci. 2013;8:223-41

Evans ME, Rosengren KS, Lane JD, Price KLS. Encountering counterintuitive ideas. Constructing a developmental learning progression for evolution understanding. In: Rosengren K, Brem SK, Evans EM, Sinatra GM, editors.
Evolution challenges: integrating research and practice in teaching and learning about evolution. New York: Oxford University Press; 2012. p. 174-9.

Galli LMG, Meinardi EN. The role of teleological thinking in learning the Darwinian model of evolution. Evol Educ Outreach. 2011:4:145-52.

Ginsborg H. Kant's biological teleology and its philosophical significance. In: Bird G, editor. A companion to Kant. Oxford: Wiley-Blackwell; 2006. p. 455-70.

Goudge TA. The ascent of life. A philosophical study of the theory of evolution. Toronto: University of Toronto Press; 1961.

Gresch H, Martens M. Teleology as a tacit dimension of teaching and learning evolution: a sociological approach to classroom interaction in science education. J Res Sci Teach. 2019;56:243-69.

Griffiths PE. Functional analysis and proper functions. Br J Philos Sci. 1993:44:409-22.

Grünewald B. Teleonomie und reflektierende Urteilskraft [Teleonomy and reflective judgment]. In: Riebel A, Hiltscher R, editors. Wahrheit und Geltung. Festschrift für Werner Flach [Truth and validity. Commemorative publication for Werner Flach]. Würzburg: Königshausen \& Neumann; 1996. p. 63-84

Halldén O. The evolution of the species: pupil perspectives and school perspectives. IJSE. 1988;10:541-52.

Halls JG, Ainsworth SE, Oliver MC. Young children's impressionable use of teleology: the influence of question wording and questioned topic on teleological explanations for natural phenomena. IJSE. 2018;40:808-26.

Hegel GWF. Wissenschaft der Logik ([Science of logic]). Cited after: Moldenhauer E, Michel KM, editors. G.W.F. Hegel Werke. Bd. 5 \& 6. [G.W.F. Hegel works. Volumes 5 \& 6]. Frankfurt: Suhrkamp; 1986.

Hornbergs-Schwetzel S. Der Funktionsbegriff in den Lebenswissenschaften: wissenschaftstheoretischer Status und normative Implikationen [The concept of function in the life sciences: scientific theory status and normative implications]. Bonn: Universität Bonn; 2012.

Höst GE, Anward J. Intentions and actions in molecular self-assembly: perspectives on students' language use. IJSE. 2017;39:627-44.

Hove JR, Köster RW, Forouhar AS, Acevedo-Bolton G, Fraser SE, Gharib M. Intracardiac fluid forces are an essential epigenetic factor for embryonic cardiogenesis. Nature. 2003;421:172-7

Hughes A. Anthropomorphism, teleology, animism, and personification-why they should be avoided. Sci Child. 1973;10:10-1.

Huxley J. The openbill's open bill: a teleonomic enquiry. Zool Jahrb. 1960-61;80:9-29.

Illetterati L, Michelini F. Purposiveness: teleology between nature and mind. Heusenstamm: Ontos; 2008.

Jacobs J. Teleology and reduction in biology. Biol Philos. 1986;1:389-99.

Järvilehto $L$. The nature and function of intuitive thought and decision making. Cham: Springer; 2015.

Jensen MS, Finley FN. Changes in students' understanding of evolution resulting from different curricular and instructional strategies. J Res Sci Teach. 1996:33:879-900.

Jiménez-Aleixandre MP. Thinking about theories or thinking with theories?: a classroom study with natural selection. IJSE. 1992;14:51-61.

Kahneman D. Thinking, fast and slow. London: Penguin; 2012.

Kampourakis K. The Finches' beaks: introducing evolutionary concepts. Sci Scope. 2006;29:14-7.

Kampourakis K. Teaching about adaptation: why evolutionary history matters. Sci Educ. 2013;22:173-88.

Kampourakis K, Zogza V. Students' intuitive explanations of the causes of homologies and adaptations. Sci Educ. 2008;17:27-47.

Kampourakis K, Zogza V. Preliminary evolutionary explanations: a basic framework for conceptual change and explanatory coherence in evolution. Sci Educ. 2009;18:1313-40.

Kampourakis K, Palaiokrassa E, Papadopoulou M, Pavlidi V, Argyropoulou M. Children's intuitive teleology: shifting the focus of evolution education research. Evol Educ Outreach. 2012a:5:279-91.

Kampourakis K, Pavlidi V, Papadopoulou M, Palaiokrassa E. Children's teleological intuitions: what kind of explanations do 7-8 year olds give for the features of organisms, artifacts and natural objects? Res Sci Educ. 2012b:42:651-71.

Kant I. Critique of judgment. 1790/93. Translated by Pluhar WH. Cambridge: Hackett Publishing; 1987. 
Keil FC. The emergence of an autonomous biology. In: Gunnar M, Maratsos $M$, editors. Modularity and constraints in language and cognition: the Minnesota symposia. Hillsdale: Earlbaum; 1992. p. 103-38.

Keil FC. The growth of causal understandings of natural kinds. In: Sperber D, Premack D, Premack AJ, editors. Symposia of the Fyssen Foundation. Causal cognition: a multidisciplinary debate. New York: Clarendon Press/Oxford University Press; 1995. p. 234-67.

Kelemen D. Why are rocks pointy? Children's preference for teleological explanations of the natural world. Dev Psychol. 1999:35:1440-52.

Kelemen D. British and American children's preferences for teleo-functional explanations of the natural world. Cognition. 2003;88:201-21.

Kelemen D. Teleological minds: how natural intuitions about agency and purpose influence learning about evolution. In: Rosengren K, Brem SK, Evans EM, Sinatra GM, editors. Evolution challenges: integrating research and practice in teaching and learning about evolution. New York: Oxford University Press; 2012. p. 66-92.

Kelemen D, DiYanni C. Intuitions about origins: purpose and intelligent design in children's reasoning about nature. J Cogn Dev. 2005;6:3-31.

Kelemen D, Rottman J, Seston R. Professional physical scientists display tenacious teleological tendencies: purpose-based reasoning as a cognitive default. J Exp Psychol Gen. 2013;142:1074-83.

Koutroufinis SA. Biological neo-teleologism versus Aristotle's genuine telos. Biocosmol-Neo-Aristot. 2016;6:414-26

Krafft F. Das Verdrängen teleologischer Denkweisen in den exakten Naturwissenschaften [The suppression of teleological ways of thinking in the exact natural sciences]. In: Poser $\mathrm{H}$, editor. Formen teleologischen Denkens. Philosophische und wissenschaftshistorische Analysen [Kinds of teleological thinking. Philosophical and science-historical analyses]. Colloquium at the TU Berlin winter semester 1980/81. TUB documentation of congresses and conferences, Issue 11. 1981. p. 31-59.

Krohs U. Eine Theorie biologischer Theorien: Status und Gehalt von Funktionsaussagen und informationstheoretischen Modellen [A theory of biological theories: Status and content of functional statements and information theoretic models]. Berlin: Springer; 2004.

Krohs U. Der Funktionsbegriff in der Biologie [The concept of function in biology]. In: Bartels A, editor. Wissenschaftstheorie: ein Studienbuch [Philosophy of science: a study book]. Paderborn: Mentis; 2007. p. 287-306.

Krohs U. Semiotic explanation in the biological sciences. In: Kaiser MI, Hüttemann A, Plenge D, Scholz OR, editors. Synthese library, studies in epistemology, logic, methodology, and philosophy of science: vol 367 Explanation in the special sciences: the case of biology and history. Dordrecht: Springer; 2014. p. 87-98.

Krohs U, Kroes P. Philosophical perspectives on organismic and artifactual functions. In: Krohs U, Kroes P, editors. Functions in biological and artificial worlds: comparative philosophical perspectives. Berlin: Springer; 2009. p. 3-12.

Kullmann W. Wesen und Bedeutung der 'Zweckursache' bei Aristoteles [Nature and meaning of the 'final cause' in Aristotle]. Ber Wiss. 1982;5:25-39.

Lennox JG. Teleology. In: Keller EF, Lloyd EA, editors. Keywords in evolutionary biology. Cambridge: Harvard University Press; 1992. p. 324-33.

Lennox JG. Teleology by another name: a reply to Ghiselin. Biol Philos. 1994;9:493-5

Levin M, Thorlin T, Robinson KR, Nogi T, Mercola M. Asymmetries in $\mathrm{H}+/ \mathrm{K}+-$ ATPase and cell membrane potentials comprise a very early step in left-right patterning. Cell. 2002;111:77-89.

Lorenz K. Die Rückseite des Spiegels. Versuch einer Naturgeschichte menschlichen Erkennens [Behind the mirror: a search for a natural history of human knowledge]. München: Deutscher Taschenbuch Verlag; 1973.

Löw R. Philosophie des Lebendigen. Der Begriff des Organischen bei Kant, sein Grund und seine Aktualität [Philosophy of the living. The concept of the organic in Kant, its reason and its topicality]. Frankfurt: Suhrkamp; 1980.

Machamer P, Darden L, Craver CF. Thinking about mechanisms. Philos Sci. 2000;67:1-25

Matsunaga E, Okanoya K. Evolution and diversity in avian vocal system: an Evo-Devo model from the morphological and behavioral perspectives. Dev Growth Var. 2009:51:355-67.

Mayr E. Cause and effect in biology: kinds of causes, predictability, and teleology are viewed by a practicing biologist. Science. 1961;134:1501-6.

McLaughlin P. What functions explain: functional explanation and selfreproducing systems. Cambridge studies in philosophy and biology. Cambridge: Cambridge University Press; 2001.
Mead LS, Scott EC. Problem concepts in evolution. Part I: purpose and design. Evol Educ Outreach. 2010;3:78-81.

Michael JA. Students' misconceptions about perceived physiological responses. Adv Physiol Educ. 1998;274:590-8.

Ministry of Education and Training of the State of North Rhine-Westphalia. Kernlehrplan für das Gymnasium - Sekundarstufe I in Nordrhein-Westfalen - Biologie [Core curriculum for high school-lower secondary level in North Rhine-Westphalia-biology]. 2008.

Moore R, Mitchell G, Bally R, Inglis M, Day J, Jacobs D. Undergraduates' understanding of evolution: ascriptions of agency as a problem for student learning. J Biol Educ. 2002;36:65-71.

Mossio M, Saborido C, Moreno A. An organizational account of biological functions. Br J Philos Sci. 2009:60:813-41.

Neander K. The teleological notion of 'function'. Australas J Philos. 1991;69:454-68.

Nehm RH, Ridgway J. What do experts and novices "see" in evolutionary problems? Evol Educ Outreach. 2011;4:666-79.

Nehm RH, Beggrow EP, Opfer JE, Ha M. Reasoning about natural selection: diagnosing contextual competency using the ACORNS instrument. Am Biol Teach. 2012;74:92-8.

Olson EN. Gene regulatory networks in the evolution and development of the heart. Science. 2006:313:1922-7.

Opfer JE, Nehm RH, Ha M. Cognitive foundations for science assessment design: knowing what students know about evolution. J Res Sci Teach. 2012:49:744-77.

Paley W. Collected works, 4: natural theology. London: Rivington; 1819.

Pedersen S, Halldén O. Intuitive ideas and scientific explanations as parts of students' developing understanding of biology: the case of evolution. Eur J Psychol Educ. 1994;9:127-37.

Perlman M. The modern philosophical resurrection of teleology. Monist. 2004:87:3-51.

Perlman M. Changing the mission of theories of teleology: DOs and DON'Ts for thinking about function. In: Krohs $U$, Kroes $\mathrm{P}$, editors. Functions in biological and artificial worlds: comparative philosophical perspectives. Berlin: Springer; 2009. p. 17-36.

Pinxten R, Desclée M, Eens M. Upper secondary and first-year university students' explanations of animal behaviour: to what extent are Tinbergen's four questions about causation, ontogeny, function and evolution, represented? IJSE. 2016;38:2303-25.

Pittendrigh C. Adaptation, natural selection and behavior. In: Roe A, Simpson GG, editors. Behavior and evolution. New Haven: Yale University Press; 1958. p. 390-416.

Plato (Tim.). Timaios. Cited after: Müller H. In: Otto WF, Grassi E, Plamböck G, editors. Platon. Platon Sämtliche Werke Bd. 5 [Plato complete works vol 5]. Hamburg: Rowohlt; 1959.

Poling DA, Evans EM. Why do birds of a feather flock together? Developmental change in the use of multiple explanations: intention, teleology and essentialism. Br J Dev Psychol. 2002;20:89-112.

Prior EW. What is wrong with etiological accounts of biological function? Pac Philos Q. 1985;66:310-28.

Quarfood M. Kant on biological teleology: towards a two-level interpretation. Stud Hist Philos Biol Biomed Sci. 2006;37:735-47.

Ratcliffe M. The function of function. Stud Hist Philos Sci A. 2000:31:113-33.

Raya Á, Kawakami Y, Rodríguez-Esteban C, Ibañes M, Rasskin-Gutman D, Rodríguez-León J, et al. Notch activity acts as a sensor for extracellular calcium during vertebrate left-right determination. Nature. 2004:427:121-8.

Richardson DR. A survey of students' notions of body function as teleologic or mechanistic. Am J Physiol. 1990;258:8-10.

Rosenblueth A, Wiener N, Bigelow J. Behavior, purpose and teleology. Philos Sci. 1943;10:18-24.

Saxon State Ministry of Education and Sports. Lehrplan Gymnasium - Biologie [Curriculum for high school-biology]. 2011. http://www.schule.sachs en.de/lpdb/web/downloads/1394_Ip_gy_biologie_2017.pdf?v2.

Sealey A, Oakley L. Why did the Canada goose cross the sea? Accounting for the behaviour of wildlife in the documentary series Life. Int J Appl Linguist. 2014;24:19-37.

Searle J. The construction of social reality. New York: Simon \& Schuster; 1995.

Settlage J. Conceptions of natural selection: a snapshot of the sense-making process. J Res Sci Teach. 1994;31:449-57. 
Sinatra GM, Brem SK, Evans EM. Changing minds? Implications of conceptual change for teaching and learning about biological evolution. Evol Educ Outreach. 2008;1:189-95.

Sommerhoff G. Analytical biology. London: Oxford University Press; 1950.

Srivastava D, Olson EN. A genetic blueprint for cardiac development. Nature. 2000;407:221-6.

Stern F, Kampourakis K, Huneault C, Silveira P, Müller A. Undergraduate biology students' teleological and essentialist misconceptions. Educ Sci. 2018:8:135.

Stover S, Mabry M. Influences of teleological and lamarckian thinking on student understanding of natural selection. Bioscene. 2007;33:11-8.

Tamir P, Zohar A. Anthropomorphism and teleology in reasoning about biological phenomena. Sci Educ. 1991;75:57-67.

Toepfer G. Zweckbegriff und Organismus: Über die teleologische Beurteilung biologischer Systeme [Purpose and organism: on the teleological judgment of biological systems]. Würzburg: Königshausen \& Neumann; 2004

Toepfer G. Teleology in natural organized systems and in artefacts: interdependence of processes versus external design. In: Illetterati L, Michelini F, editors. Purposiveness: teleology between nature and mind. Frankfurt: Ontos; 2008. p. 163-81.

Toepfer G. Historisches Wörterbuch der Biologie: Geschichte und Theorie der biologischen Grundbegriffe. Band 1: Analogie - Ganzheit. [Historical dictionary of biology: history and theory of basic biological terms. Volume 1: analogy—holism]. Stuttgart: Metzler; 2011.

Toepfer $\mathrm{G}$. Teleology and its constitutive role for biology as the science of organized systems in nature. Stud Hist Philos Biol Biomed Sci. 2012;43:113-9.
Trommler F, Gresch H, Hammann M. Students' reasons for preferring teleological explanations. IJSE. 2018;40:159-87.

van Hateren $\mathrm{JH}$. A unifying theory of biological function. Biol Theory. 2017;12(2):112-26.

Varela FG, Maturana HR, Uribe R. Autopoiesis: the organization of living systems, its characterization and a model. BioSystems. 1974;5:187-96.

Walsh DM, Ariew A. A taxonomy of functions. In: Buller DJ, editor. SUNY series in philosophy and biology Function, selection and design. Albany: State University of New York Press; 1999. p. 257-80.

Weber M. How objective are biological functions? Synthese. 2017;194(12):4741-55.

Weber A, Varela FJ. Naturalizing teleology: towards a theory of biological subjects. In: Illetterati L, Michelini F, editors. Purposiveness: teleology between nature and mind. Frankfurt: Ontos; 2008. p. 201-19.

Weitzel H. Biologie verstehen: Vorstellungen zu Anpassung [Understanding biology: ideas about adaptation]. Oldenburg: Didaktisches Zentrum Universität Oldenburg; 2006.

Wright L. Functions. Philos Rev. 1973;82:139-68.

Wright L. Teleological explanations: an etiological analysis of goals and functions. California: University of California Press; 1976.

Zohar A, David AB. Explicit teaching of meta-strategic knowledge in authentic classroom situations. Metacogn Learn. 2008;3:59-82.

Zohar A, Ginossar S. Lifting the taboo regarding teleology and anthropomorphism in biology education-heretical suggestions. Sci Educ 1998;82:679-97.

\section{Publisher's Note}

Springer Nature remains neutral with regard to jurisdictional claims in published maps and institutional affiliations.
Ready to submit your research? Choose BMC and benefit from:

- fast, convenient online submission

- thorough peer review by experienced researchers in your field

- rapid publication on acceptance

- support for research data, including large and complex data types

- gold Open Access which fosters wider collaboration and increased citations

- maximum visibility for your research: over $100 \mathrm{M}$ website views per year

At BMC, research is always in progress.

Learn more biomedcentral.com/submissions 